\title{
Circumstances of death in sudden death in epilepsy: interviews of bereaved relatives
}

\author{
L Nashef, S Garner, J W A S Sander, D R Fish, S D Shorvon
}

\begin{abstract}
Objectives-To study the circumstances of death in sudden death in epilepsy.

Methods-Self referred bereaved relatives of patients with epilepsy who had died suddenly were interviewed with information obtained substantiated through other sources-namely, coroners' officers' reports, postmortem reports, previous medical records, and EEG reports.

Results-Of 34 cases, 26 were classified as sudden unexpected deaths in epilepsy (SUDEP). Twenty four of 26 cases of SUDEP were unwitnessed. Evidence indicative or suggestive of a seizure was found in most. In 11 of 26 the position of the head was such that breathing could have been compromised. Cases included both localisation related and idiopathic primary generalised epilepsy. Only three were in remission at the time of death. Most relatives expressed the view that they would have preferred to have known that epilepsy could be fatal.

Conclusions-Although the deaths in question were largely unwitnessed, the available evidence suggested that most cases of SUDEP represented ictal or postictal seizure deaths, occurring in people with a history of generalised tonic clonic seizures, and in both primary generalised and localisation related epilepsy. These interviews highlight the needs of bereaved relatives and their sense of isolation in the face of an entirely unexpected and apparently unexplained loss.
\end{abstract}

(F Neurol Neurosurg Psychiatry 1998;64:349-352)

Keywords: sudden death in epilepsy

Sudden unexpected death in epilepsy (SUDEP) is now widely recognised, ${ }^{1-18}$ yet there is no agreement on classification of a terminal event, which is usually unwitnessed and incompletely documented. Some separate out likely seizure deaths ${ }^{9}{ }^{10}{ }^{17}$ whereas others think that most cases of SUDEP are seizure related. ${ }^{11}$

Bereaved relatives were interviewed to document circumstances of death.

\section{Methods}

Relatives were referred mainly through the self help group "Epilepsy Bereaved?". ${ }^{17}$ Detailed semistructured interviews by a physician (LN) and nurse (SG) covered circumstances of death and medical and social history. Additional information included death certificates, coroner's officer's reports, and postmortem find- ings. Previous medical records were sought. Classification of epilepsy was based on the recommendations of the International League against Epilepsy Commission (1989). ${ }^{18}$

SUDEP was defined to include nontraumatic and non-drowning sudden unexpected death in patients with epilepsy, with or without evidence of a seizure, and excluding witnessed status epilepticus, in which postmortem examination did not disclose a cause for death. Cases with minor aspiration, bronchial secretions, and pulmonary oedema (an often reported postmortem finding) were included, as were those with possible asphyxiation. Those found in the bath were only included if there was no evidence of submersion. Reasons for this working definition have been previously outlined. ${ }^{6}$

\section{Results}

Thirty four interviews were conducted in 1993-4. Key persons interviewed included parent(s) (23), sibling (five) spouse or partner (seven), and key worker (one) with additional information from two observers. The interval between interview and death ranged from less than one year (13) to more than five years (four). The body was found or death was witnessed by one interviewee in 21 of 34 cases (14 SUDEP).

DEATHS NOT CATEGORISED AS SUDEP (EIGHT)

There was doubt about the diagnosis of epilepsy in an untreated teenager who collapsed with rigidity although the cause of death had been certified as "epileptic fit". Postmortem showed anoxic damage and more chronic inflammatory changes in the medulla. Two cases were found with the face partly or totally submerged in water and dry drowning could not be ruled out. Two men (aged 34 and 63) died in witnessed habitual generalised tonic clonic seizure lasting two to three minutes. Postmortem showed significant ischaemic heart disease considered as the cause of death. Epilepsy was certified a contributory factor in only one.

One (aged 10 with idiopathic primary generalised epilepsy) was heard to convulse and was found collapsed, having vomited. Postmortem showed severe aspiration. Certified cause of death was aspiration of gastric contents (due to) acute epilepsy. Another, aged 24 with primary generalised epilepsy, was found with a bitten tongue and a food bolus occluding the larynx. Cause of death was certified as asphyxia, (due to) food inhalation (due to) epilepsy.

One man (aged 72 years, epilepsy onset at 62 ) with vascular disease and four complex 


\section{Table 1 Evidence for seizure in 26 cases of SUDEP}

\begin{tabular}{ll}
\hline 1 & Bitten tongue, incontinent of urine, blood in corner of mouth \\
2 & Bitten tongue (several places) and lip, blood/mucus nares \\
3 & Bitten tongue, disrupted environment, fallen off bed \\
4 & Died am soon after waking; timing of habitual seizures \\
5 & Died early am after waking; timing of habitual seizures \\
6 & Found dead near video/TV screen - PGE, clinical and EEG photosensitivity; \\
& previous GTCS only in similar circumstances \\
8 & Fall off bed, incontinent of urine, bruised tip of tongue \\
10 & Died am soon after waking after a late night out, JME, timing of habitual seizures \\
11 & Incontinent of urine \\
12 & Partial fall off bed \\
13 & No good evidence; disrupted environment, fall off chair \\
14 & Incontinent of urine, pink/bloodstained secretions on pillow \\
17 & Contorted facial expression as in a seizure \\
18 & Bitten tongue, computer game on, JME, known photosensitivity \\
19 & Witnessed tonic clonic seizure \\
22 & Partial fall off bed, facial expression as in a seizure \\
23 & Bitten lip, secretions \\
24 & Fall off bed, nocturnal attacks only \\
25 & No evidence \\
26 & No evidence \\
28 & Bitten lip, incontinent of urine \\
29 & Incontinent of urine \\
30 & Bitten tongue, partial fall off bed, incontinent of urine \\
31 & Tongue clenched between teeth \\
32 & Secretions, tongue clenched between teeth \\
33 & Witnessed tonic clonic seizure \\
\hline
\end{tabular}

Cases 7, 9, 15, 16, 20, 21, 27 and 34 were excluded (see text).

$\mathrm{PGE}=$ primary generalised epilepsy; GTCS $=$ generalised tonic clonic seizure.

$\mathrm{JME}=$ juvenile monoclonic epilepsy.

partial seizures in the 24 hours before death was unclassified. Two hours after the last nocturnal complex partial seizure, the person, from sleep, exhaled with force, briefly shaking his head before dying. At postmortem, the heart was enlarged with thrombus in the ventricle and an atheromatous but patent left anterior descending artery. Whether an ictal discharge contributed to a cardiac death is uncertain.

CASES OF SUDEP

There were 26 cases of SUDEP of Eurasian extraction (12 female, 14 male), one of whom was found in the bath with tongue biting and no evidence of submersion. All cases of SUDEP were referred to the coroner and underwent postmortem examination. The report was available in 25 of 26 cases and the death certification in all. Coroners' officers' summaries, previous clinical summaries or records, and EEG reports were available in 21, 22 , and 24 cases respectively. Age range at death was $14-51$ (mean 27 ) years with 25 aged between 14 and 36. Mean age of onset of epilepsy was 16 (range 1-33) years and mean duration was 11.5 (range 1-29) years. There were 11 in full employment, three part time, six students, one pupil, and five unemployed. At least 22 were considered of normal intelligence. One had a history of self harm.

Of 26 cases, 11 had generalised epilepsy (nine primary generalised epilepsy), 10 localisation related epilepsy, and five were undetermined. Patients classified as having primary generalised epilepsy had generalised spike/wave on EEG and a consistent clinical syndrome. Of the patients classified as having localisation related epilepsy, two had post-traumatic epilepsy, one previous encephalitis, and two febrile convulsions. No family history of sudden nonischaemic cardiac death was obtained.

Postmortem findings included variable congestion of organs, most commonly the lungs.
Toxicology was performed in at least eight cases. Certified causes of death included status epilepticus (nine), epilepsy or epileptic attack (seven), epileptic seizure with mechanism proposed (for example, asphyxia, respiratory failure, bronchial secretions, anoxia, cerebral ischaemia, hypotension) (seven), sudden unexpected death in epilepsy (one), and unascertained (two). Epilepsy was mentioned in all but two.

Deaths occurred in sleep in at least 12 of 26 cases of SUDEP (three uncertain). Two people (both with primary generalised epilepsy) were found on the floor near a video display unit. Both had had seizures in similar circumstances and photosensitivity on EEG. One had reportedly never been treated and it was reported that the other recently discontinued medication. In five of 26 cases the person died face down in the pillow and in one into carpet pile. In a further five the position of the head may have compromised breathing. Two of 26 were witnessed. One person got up confused within minutes of a witnessed tonic clonic seizure and collapsed with no further convulsive movements. In the second case a nocturnal tonic clonic seizure seizure lasting a few minutes ended with stentorous breathing. The person remained unconscious and face down. In unwitnessed cases, some evidence for a seizure was found in 21 of 24 (table 1).

Estimated total lifetime tonic clonic seizure were: eight less than 10, 10 between 10 and 100, and seven greater than 100 (one unknown with no tonic clonic seizure reported for over 20 years). Five had a history of status epilepticus or serial seizures. Table 2 shows the frequency of tonic clonic seizure.

Two had never been treated. Patients were taking none to three antiepileptic drugs (mean 1.7). Compliance was reported to be generally poor in one and unknown in another. A third, usually compliant, omitted one dose of phenytoin three days before death. Another had reportedly discontinued medication independently. The remainder were reported to be compliant, although one of three in remission (defined as a seizure free period of at least two years on or off treatment) had been contemplating reduction. In another, medication was being withdrawn. Other prescribed reductions within four weeks of death included two with phenytoin withdrawal. In one, previously on monotherapy, phenytoin was being substituted by carbamazepine because partial seizures were uncontrolled. The evening before an unwitnessed nocturnal death, a witnessed tonic clonic seizure occurred for the first time in 10

Table 2 Frequency of tonic clonic seizures in 26 cases of SUDEP

\begin{tabular}{ll}
\hline$\geqslant 1 /$ day & None \\
$\geqslant 1 /$ week & 2 \\
$\geqslant 1 /$ month & 9 \\
$\geqslant 1 / 3$ months & 5 \\
$\geqslant 1 /$ y & 4 \\
$\geqslant 1 / 5$ y & $2^{\star}$ \\
$<1 / 5$ y & $3 \dagger$ \\
Unknown & 1
\end{tabular}

* Medication being withdrawn in one; the second person had discussed drug withdrawal; not known if carried out. t Minor seizures $>1 / 3$ months. 
months. Of nine with primary generalised epilepsy, one had reportedly never been treated, and one, already mentioned, had reportedly discontinued medication independently. One, referred to above, with juvenile myoclonic epilepsy in remission on valproate had been considering reduction. One had only ever been treated with carbamazepine, and the other with phenytoin.

One woman with infrequent convulsions was in the second trimester of pregnancy. One person with post-traumatic epilepsy and major facial reconstructive surgery was concerned that facial deformity could compromise breathing during seizures. Another with asthma had been found collapsed and was resuscitated four years previously. One had postmortem evidence of a recent head injury not considered the cause of death. Fatigue or sleep deprivation was reported in two others with uncontrolled primary generalised epilepsy. None were reported as drinking excessively before death.

Many relatives had either been categorically told, or led to believe, that epilepsy could not be fatal. Most stated in retrospect that they would have preferred to know of the possibility of premature death, however remote.

\section{Discussion}

Epilepsy related deaths are either treatment or seizure related. Seizure related deaths include those in status epilepticus and deaths in the setting of a single seizure. Causes of death secondary to a seizure include trauma or drowning, severe aspiration or obstruction due to a food bolus, or death during a habitual seizure in the presence of significant unrelated pathology such as ischaemic heart disease. The possibility that those with both ischaemic heart disease and chronic epilepsy may be more at risk of seizure related deaths deserves further study.

The most common category, however, is that where persons with epilepsy die suddenly and unexpectedly in the absence of an anatomical or toxicological cause. Although postmortem examination is often abnormal with findings of oedema of organs, particularly lungs, bronchial secretions, or minor aspiration, these are not sufficient to cause death. Most of these deaths are unwitnessed, making it difficult to ascertain if they occurred peri-ictally. The nature of evidence for a seizure (found in about half of 60 cases) was not stated in the largest recent coroners' series reported. ${ }^{16}$

More detailed information was obtained in our study than is usual and the proportion with evidence for a seizure higher than previously reported, although such evidence is suggestive and not absolute. It is of note that only two (of 14 finding the body) of those interviewed reported a very distorted facial expression, suggesting that most deaths were not instantaneous during the tonic phase. In the two witnessed cases the death was post-ictal. As in previous studies, the cause of death was often inappropriately certified as status epilepticus. This study supports the view that most cases of SUDEP are ictal or peri-ictal, and one focus for prevention of these deaths lies in controlling seizures. In emphasising this, we do not exclude the possibility that in epidemiological studies, in which information is often limited, a few may represent non-ictal cardiac arrhythmias or cardiac disorders misdiagnosed as epilepsy.

Theories of mechanisms in SUDEP focus on hypoventilation and cardiac changes occurring during or immediately after a seizure. ${ }^{19}{ }^{20}$ It is not possible, on the basis of postmortem findings, to reliably separate out cases with "asphyxia". Petechial haemorrhages are not specific, occurring in hypoxia and raised cephalic venous pressure, ${ }^{21}$ both found during seizures, and with attempted resuscitation. ${ }^{22}$ Smother proof pillows have been historically recommended and nocturnal SUDEP deaths have often been blamed on suffocation. ${ }^{23}$ In this study, only five people were found face down in the pillow, and a sixth with the head in carpet pile. Thus such pillows, if protective, are only relevant in a minority. There were, however, 11 of 26 cases in which an extrinsic or intrinsic positional obstruction to breathing amenable to intervention may have contributed. This may be an underestimate as obstructive apnoea can occur in an apparently benign position. ${ }^{20}$

SUDEP occurs in both symptomatic epilepsies and primary generalised epilepsy. The results are in keeping with epidemiological evidence that SUDEP is rare in remission. ${ }^{24} \mathrm{~A}$ history of tonic clonic seizure is usually obtained, although deaths in other seizure types have been exceptionally reported. ${ }^{3}$ It is likely that tonic clonic seizures constitute a much greater risk to life than other types of seizures. Among SUDEP cases in this study only one had uncontrolled complex partial seizures alone, the last tonic clonic seizure being at least 20 years before death.

Excessive alcohol intake is well documented but was not a feature here. Only a few cases in this study were reportedly non-compliant and in some recent prescribed medication changes were recorded. Both alcohol excess and medication withdrawal can precipitate seizures, but may also predispose to autonomic instability thus increasing the risk of ictal death. Further work is required on ictal and interictal changes after withdrawal of antiepileptic drugs The potential relation between SUDEP and head injury is of interest. Gastaut and Gastaut noted the occurrence of syncope, usually within a few weeks, in $5.6 \%$ of head injuries. ${ }^{25}$ This they attributed to vagal hyperreactivity. Although usually a benign and transient phenomenon, this may predispose to secondary ictal bradyarrhythmia.

Only two of 26 of the cases of SUDEP were witnessed (six of 34 for the whole group). Whereas there may be selection bias in self referral, this is broadly in keeping with other published reports. One possible explanation for this finding is that witnessed seizures are less likely to be fatal, and that timely assistance may prevent some of these deaths - for example, by positioning and stimulating the patient and clearing the airway. ${ }^{6}$ 
Most cases of sudden death in the United Kingdom are referred to the coroner. As the entity of SUDEP becomes better known there is a risk that full assessment would not be carried out. We think that all cases should undergo adequate postmortem examination and toxicology.

These deaths were unexpected in a chronic condition labelled as benign but requiring much support. Bereaved relatives felt isolated in their apparently unexplained loss and often expressed feelings of guilt or blame. Counselling was not usually offered. Contact with the general practitioner and specialist was helpful but was sometimes limited or absent. Many would have preferred that the risks associated with epilepsy had been acknowledged, and regretted that they and their deceased relative had not had the opportunity of making informed decisions regarding lifestyle and treatment. We recommend that information about mortality and response to seizures is included in leaflets on epilepsy, and that in the event of SUDEP, the general practitioner makes early contact with bereaved relatives and that the consultant or specialist writes with an open offer of a meeting. Information about the self help group "Epilepsy Bereaved?", other supporting agencies, and counselling services should also be given as appropriate.

We thank Action Research for funding this project and all physicians, coroners, and coroners' officers who kindly responded to our requests. We are also very grateful to individual and founding members of "Epilepsy Bereaved?" for sharing with us their tragic experiences. This study was funded by Action Research.

1 Nashef L. Sander JWAS. Sudden unexpected deaths in epilepsy - where are we now? Seizure 1996;5:235-238.

2 Nashef L, Sander JWAS, Shorvon SD. Mortality in epilepsy. In: Pedley TA, Meldrum BS, eds. Recent advances in epilepsy, 6th ed. Edinburgh: Churchill Livingstone, 1995. 3 Dasheiff RM. Sudden unexpected death in epilepsy: a series
from an epilepsy surgery programme and speculation on the relationship to sudden cardiac death. $\mathcal{F}$ Clin Neurophys 1991;8:216-22

4 Tennis P, Cole TB, Annegers JF, et al. Cohort study of incidence of sudden unexplained death in persons with seizure disorder treated with antiepileptic drugs in Saskatchewan, Canada. Epilepsia 1995;36:29-36.

5 Nashef L, Sander JWAS, Fish DR, et al. Incidence of sudden unexpected death in an adult outpatient cohort with epilepsy at a tertiary referral centre. $\mathcal{F}$ Neurol Neurosurg Psychiatry 1995;58:462-4.

6 Nashef L, Garner S, Sander JWAS, et al. Sudden death in epilepsy - a study of incidence in a young cohort with epilepsy and learning difficulty. Epilepsia 1995;36:1187-94.

7 Coyle HP, Baker-Brian N, Brown SW. Coroners' autopsy reporting of sudden unexplained death in epilepsy reporting of sudden unexplained death
(SUDEP) in the UK. Seizure 1994;3:247-54

8 Timmings PL. Sudden unexpected death in epilepsy: a local audit. Seizure 1993;2:287-90.

9 Harvey AS, Nolan T, Carlin JB. Community-based study of mortality in children with epilepsy. Epilepsia 1993;34:597603.

10 Klenerman P, Sander JWAS, Shorvon SD. Mortality in patients with epilepsy: a study of patients in long term residential care. F Neurol Neurosurg Psychiatry 1993;56:149-52.

11 Nashef L, Brown S. Epilepsy and sudden death [commentary]. Lancet 1996;348:1324-5.

12 Earnest MP, Thomas GE, Randall AK, et al. The sudden unexplained death syndrome in epilepsy. Epilepsia 1992;33: 310-16.

13 Lip GYH, Brodie MJ. Sudden death in epilepsy: an avoidable outcome? $\mathcal{F} R$ Soc Med 1992;85:609-11.

14 Birnbach CD, Wilensky AJ, Dodrill CB. Predictors of early mortality and sudden death in epilepsy: a multidisciplinary approach. $\mathcal{F}$ Epilepsy 1991;4:11-7.

15 Jallon P, Haton F, Maguin P. Death among epileptics. Advances in Epileptology 1989;17:351-5.

16 Leestma JE, Walczak T, Hughes JR, et al. A prospective study on sudden unexpected death in epilepsy. Ann Neurol 1989;26:195-203.

17 Epilepsy Bereaved? POBox 1777, Bournemouth BH5 1YR. 18 Commission on Classification and Terminology of the classification of epilepsies and epileptic syndromes. Epilepsia 1989;30:389-99.

19 Johnston SC, Horn JK, Valente J, et al. The role of hypoventilation in a sheep model of epileptic sudden death. Ann Neurol 1995;37:531-7.

20 Nashef L, Walker F, Allen P, et al. Apnoea and bradycardia during epileptic seizures: relation to sudden death in epilepsy. F Neurol Neurosurg Psychiatry 1996;60:297-300.

21 Rao VJ, Welti CV. The forensic significance of conjunctival petechiae. Am f Forensic Med Pathol 1988;9:32-4.

22 Leadbeatter S, Knight B. Resuscitation artefact. Med Sci Law 1988;28:200-4.

23 Wilson JB. Hazards of epilepsy. BMF 1978;ii:200.

24 Medical Research Council Antiepileptic Drug Withdrawal Study Group. Prognostic index for recurrence of seizures after remission of epilepsy. BMF 1993;306:1374-8.

25 Gastaut H, Gastaut Y. Etude electrocliniques des syncopes posttraumatiques. Rev Neurol 1957;96:423-5. 